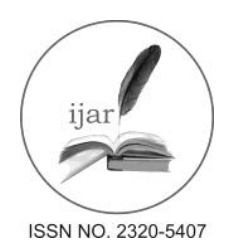

Journal homepage:http://www.journalijar.com
Journal DOI:10.21474/IJAR01

RESEARCH ARTICLE
INTERNATIONAL JOURNAL

OF ADVANCED RESEARCH

\title{
PLAYING VIDEO GAMES AND LACK OF SLEEP IN RELATION TO CHILDHOOD OBESITY AND SHORT STATURE: A POPULATION-BASED CROSS-SECTIONAL STUDY IN MADINAH, SAUDI ARABIA.
}

\author{
Ahmed Ali Alsharif, Hany Abo haded, RayyanAlqurayyan, ReemAlshenaifi, Ibrahim Alzahrani, \\ LujainAlharbi, SaadAlsehli.
}

Taibah University, Saudi Arabia .

\section{Manuscript Info}

Manuscript History:

Received: 15 April 2016

Final Accepted: 29 May 2016

Published Online: June 2016

Key words:

*Corresponding Author

Ahmed Ali Alsharif.

\section{Abstract}

Background:-Obesity and short stature among children are two of the most common problems that face the community especially in the developing countries.

Objective:- This study investigates how lack of sleep and playing videogames affects the developing of obesity and short stature in Madinah region, Saudi children.

Subjects and methods:-A cross-sectional study was conducted by using a questionnaire for information gathering about effect of lack of sleep and playing video-games on children's weight and height. About 280 parent and child in different age group from Madinah, Saudi Arabia volunteered to answer the questionnaire.

Results:-The results of the study revealed that increasing the frequency exposure to screens (watching TV and playing video games ) is significantly associated with increase the risk of developing obesity and short stature among children. the study excluded the effect of hormonal deficiency, nutritional, vitamins deficiency or chronic diseases.

Conclusion:-Watching TV, playing video games and lack of sleep may increase the risk of developing obesity and short stature in Saudi children.We advise the community to reduce the children exposure to screens and giving children enough amount of sleep will be an effective approach for improving mental and physical health, This can be done via different ways using media and health education sessions in different places may be helpful.

Copy Right, IJAR, 2016,. All rights reserved.

\section{Introduction:-}

Obesity and short stature among childrenare two of the most common problems that face the community especially in the developing countries(1). Accurate measurements of weight and height are an important part of a child's health care. In infancy, length and weight should be regularly checked at doctor visits (2).

Body mass index (BMI) is a measurement used to determine childhood overweight and obesity. Obesity is defined as a BMI at or above the 95th percentile for children and teens of the same age and sex (3).Excess weight, especially obesity, diminishes almost every aspect of health, from reproductive and respiratory function to memory and mood. Obesity increases the risk of several debilitating, and deadly diseases, including diabetes, heart disease, and some cancers . (4)

The risk factors that contribute to obesity can be a complex combination of genetics, socioeconomic factors, metabolic factors and lifestyle choices, among other things. Some endocrine disorders, diseases and medications can also cause weight to increase.(5) 
While if a child with height two or more standard deviation below the mean for children of same sex and age had a short stature, and its important to know the average height for the parents. For Men, the average height in Saudi Arabia is 1.746 and for women, the average height in Saudi Arabia is 1.625 (m).(6).

Many factors may affect how much and how rapidly a child grows, and how tall he or she will be as an adult .doctors must rule out other common causes of growth problems, such as poor nutrition, deficiencies of hormones other than growth hormone, and other illnesses(7). Short people have an increased risk of heart disease that may be partly due to their genes, a new study suggests $(\mathbf{8})$.

Physicians, researchers and trainers have been widely investigating the variables that may deeply affect the Child growth especially the anthropometric measurers .previous studies cleared that the most common causes of short stature beyond the first year or two of life are familial (genetic) short stature and delayed (constitutional) growth.(9).

Playing video-games have been increasing significantly in the last 10 years, and The typical (median) time gamers spend playing video games is five hours each week, but time spent playing video games differs considerably by country - gamers in less developed countries devote much more time to it.Saudi Arabia fall in the middle 22\%, play more than 10 hours per week. (10)

It is well documented that there is a correlation between lack of sleep and obesity ,Several studies have linked insufficient sleep and weight gain.(11). Also another studies found that sitting in front of the screen playing video games can play a part in your child developing a weight problem.(12). On the other hand, The relation between the lack of sleep and short stature was studied and resulted that sleep duration for children varies from one children to other, depending on his need, and it has no relation to somatic growth (13). However, this issue has not been discussed before in KSA.

This study investigates how lack of sleep and playing video-games affects the developing of obesity and short stature in Saudi children.

\section{Subjects and methods:- \\ Study design:-}

This is a cross-sectional study which was conducted through random sampling. The population was general population parents from Al-Madinah Al-Munwarah region in Saudi Arabia. The goal of this research was to assess the obesity and short stature among children in relation to lack of sleep and watching TV.

A predesigned structured Arabic language questionnaire was used in this cross sectional survey The questionnaires were distributed both manually and electronically on a large scale to get the effective sampling. The study sample size was 280 parents.

The used questionnaire was formulated to include both demographic, social, anthropometric, health status and educational performance. The questionnaire consisted of 58 questions. about age in years, sex(male vs. female), residence (urban vs. rural), monthly family income, weight, height, educational performance, fathers' and mothers' height, many questions about diet habit and type.

The validity of the used Arabic questionnaire was obtained from discussions with an epidemiologist and family and community medicine consultants. Approval was taken from the ethics committee at faculty of medicine, Taibah University. Ethical consideration was considered to avoid physical or emotional harm in the study questionnaire. The confidentiality and privacy of the collected data were ensured through the use of anonymous questionnaire and during data entry and analysis.People were provided with information on the study aims and methods.

The collected data were analyzed using statistical analysis system SAS (21). Data was presented using frequencies, mean and standard deviation as appropriate. Chi square tests were used to compare the studied outcome variable with the studied independent factors. The level of statistical significance was defined as $\mathrm{P} \leq 0.05$.

\section{Statistical analysis:-}

Descriptive and differential statistical measures were adapted for the analysis of the collected data. Chi-square test was used for comparison of two proportions. Also, unpaired Student's t-test was used as a test of significance for 
comparison between two arithmetic means of two different groups. The values are means \pm S.D for the students in each group. $\mathrm{p}$ value $<0.05$ was considered as significant.

\section{Results:-}

A cohort of 280 parents and their children were involved in this study. The mean age of the participated children was $9.28 \pm 4.35$ years, half of the children were male $(53.8 \%)$ and the other half were female $(46.2 \%)$. The sociodemographic data was obtained and shown in Table 1.

Table 1:-Socio-demographic characteristics of the studied subjects.

\begin{tabular}{|l|l|}
\hline Characteristics* & $\mathbf{N}=\mathbf{2 8 0}$ \\
\hline Age in years, mean \pm SD (range) & $9.28 \pm 4.35(3-18$ years) \\
\hline Sex & \\
Male & $150(53.8 \%)$ \\
Female & $130(46.2 \%)$. \\
\hline Residence:- Urban & $167(60.2 \%)$ \\
Rural & $94(33.8 \%)$ \\
\hline family income / month & \\
less than 3000 SR & $6.9 \%$ \\
$3000-5000$ SR & $7.6 \%$ \\
$5000-10000$ & $23.7 \%$ \\
$10000-15000$ & $27.7 \%$ \\
More than 15000 & $34.2 \%$ \\
\hline Living Place:- local house & $9(3.2 \%)$ \\
apartment & $162(57.7 \%)$ \\
villa & $109(39.1 \%)$ \\
\hline
\end{tabular}

*Data are presented by mean \pm SD or by $n(\%)$.

The mean \pm SD of the anthropometric measures of the participated children, their parents and its correlation with the mean measurements at birth are shown in Table 2. The results shows that the birth weight and birth length were within the normal international range. The BMI when analyzed showed obesity in $41 \%$ of the studied children. Also the mean \pm SD of the children height shows significant decrease when compared to the average height of the parents (p-value <.0001). About $19.6 \%$ of the studied children reached puberty.

Table 2:- The anthropometric measurements of the participated children and their parents.

\begin{tabular}{|l|l|}
\hline The anthropometric measurements * & $\mathbf{N}=\mathbf{2 8 0}$ \\
\hline Children height in Cms, mean \pm SD (range) & $120.6 \pm 35.18(80-150) * *$ \\
\hline Birth Length in Cms, mean \pm SD & $44.46 \pm 11.93$ \\
\hline Parent's height in Cms, mean \pm SD & $170.98 \pm 9.28$ \\
Fathers & $158.23 \pm 7.98$ \\
Mothers & $36.1 \pm 21.74(15-60)$ \\
\hline Children Weight in Kgs, mean \pm SD (range) & $3 \pm 0.83$ \\
\hline Birth Weight in Kgs, mean \pm SD & $24.5 \pm 6.9(16.5-46.2)$ \\
\hline BMI of the studied Children, mean \pm SD (range) & $168(59.1 \%)$ \\
$<25 \mathrm{~kg} / \mathrm{m}^{2}$ & $75(27.6 \%)^{* *}$ \\
$25-<30 \mathrm{~kg} / \mathrm{m}^{2}$ & $38(13.4 \%)^{* *}$ \\
$\geq 30 \mathrm{~kg} / \mathrm{m}^{2}$ & $135,(49.6 \%)$ \\
\hline Presence of Obesity in other family member:- YES & $137,(50.4 \%)$ \\
NO &
\end{tabular}

*Data are presented by mean $\pm \mathrm{SD}$ or by $\mathrm{n}(\%)$.

*Significant

Most of the children in our study $(195,69.8 \%)$ are presented by delayed sleep time. The onset of sleeping was mainly after 9pm (50.6\% between 9pm-12am, 22.7\% 7-9pm, 22.3\% 12-2am). The Causes of delayed onset of sleep were shown in Figure 1. Also the mean sleeping hours were 5-6 hour/night. More than $78.4 \%$ of the studied children showed more delay in onset of sleeping in the weekends. 


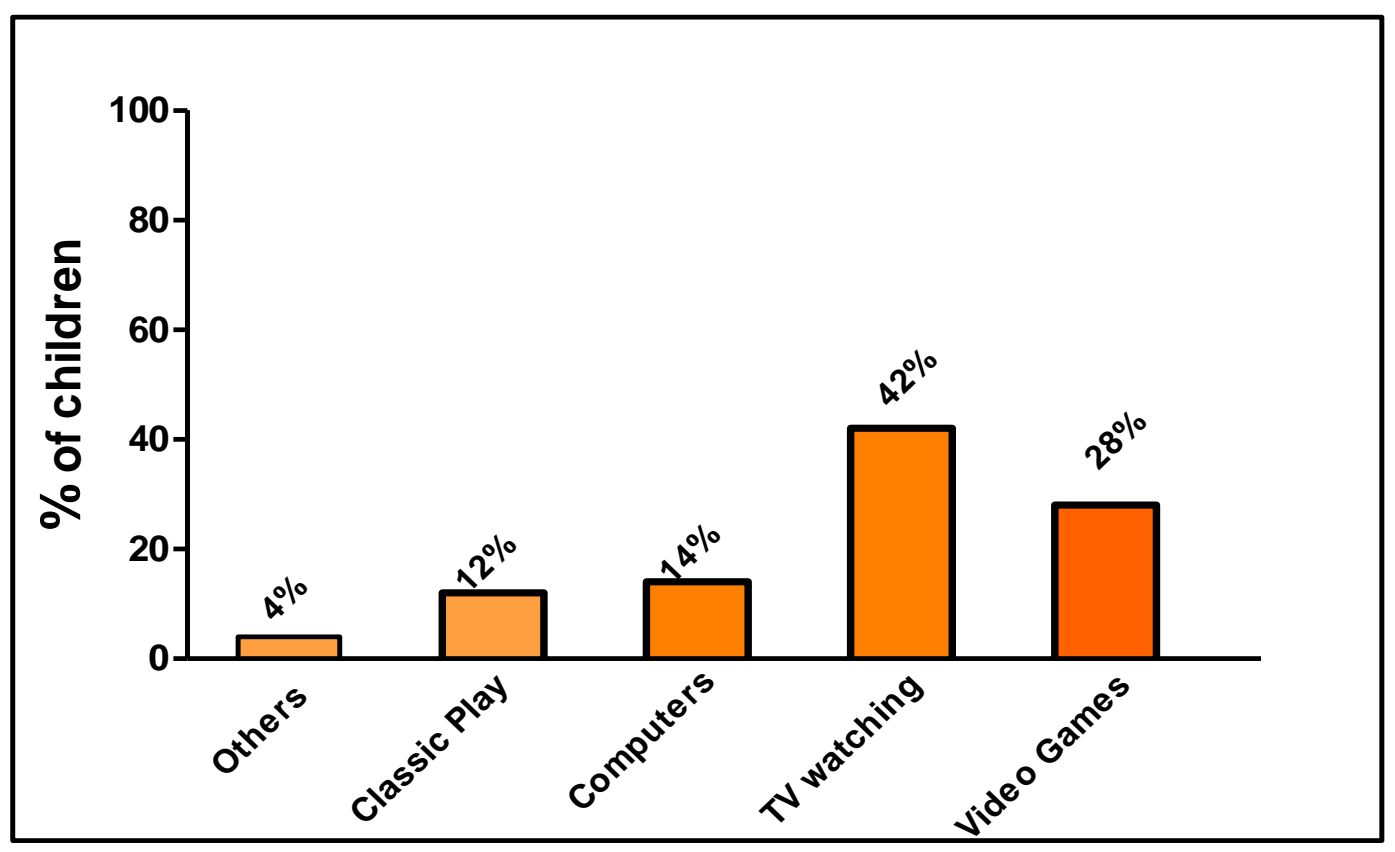

Figure 1:-Causes of delayed Onset of sleep among the studied children.

Furthermore, about $92.8 \%$ of the children have no psychological problems, $81.5 \%$ have no evidence of serious vitamin deficiency, $97.7 \%$ have no hormonal diseases. The majority of the children in our study $(94.3 \%)$ is not suffering of any chronic diseases and not maintained on any long-term drugs that can affect growth.

The parents of the studied children declared that $71.8 \%$ of the children experienced Sun exposure with a frequency of exposure ranging from $4-5$ times/week, mainly in the early morning.

There was a significant difference regarding the percentage of children who spend time dailyinfront of electronic screens (either TV watching or playing video games) and who spend time in practicing sport, see Figure 2. About $78.9 \%$ of the studied children stay infront of screens on daily bases (out of them $45.8 \%$ watch TV and play video games $1-3 \mathrm{hrs} /$ day and $21.2 \%$ reach up to $3-5 \mathrm{hrs} /$ day). while regarding practicing sports, $60.8 \%$ of the children is not practicing any type of sport per week, 25\% practice sports (Football or walking) less than 3 times/week and $14.2 \%$ practice sports more than 3times/week. 


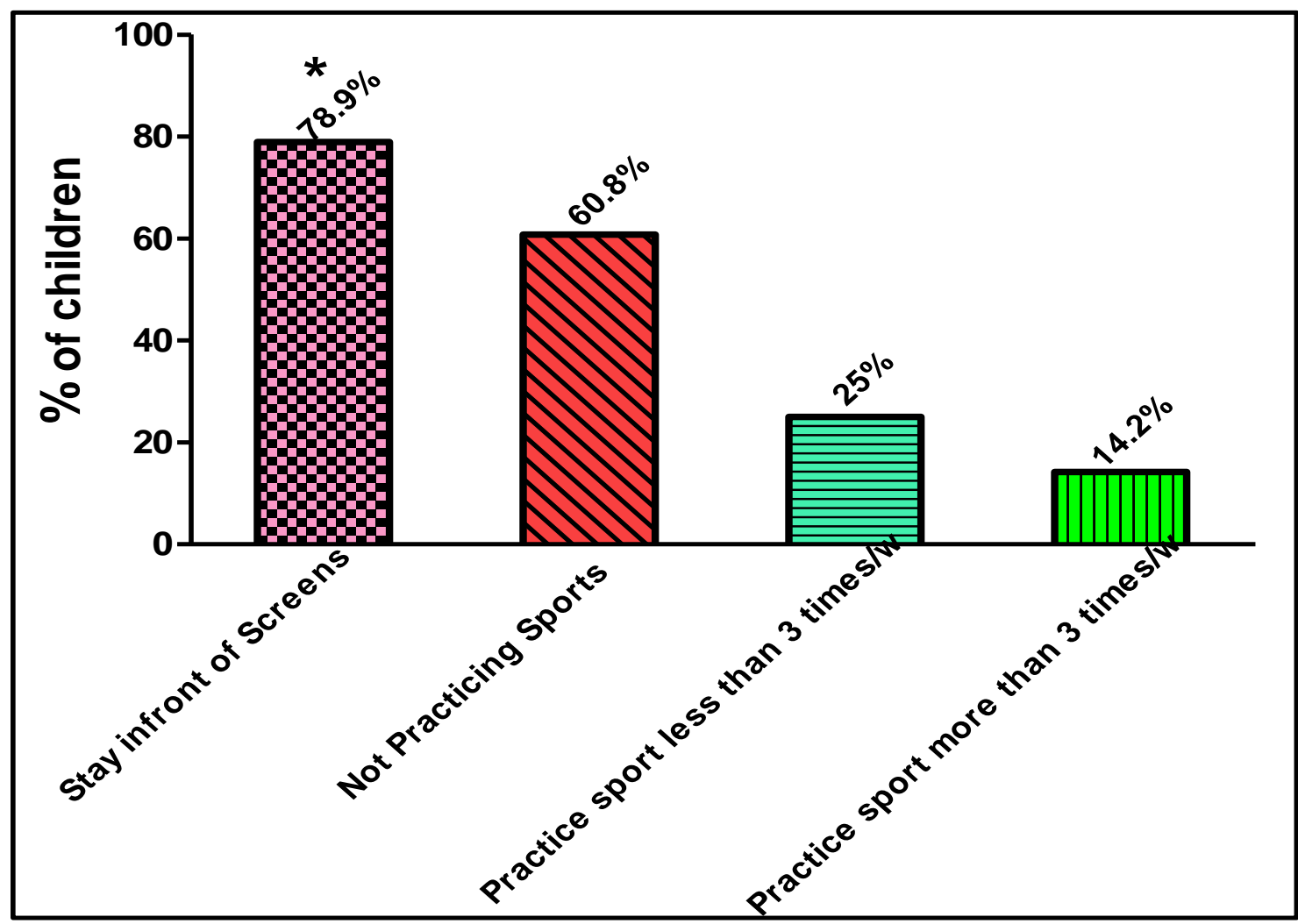

Figure 2:-The percentage of children who spend time dailyinfront of electronic screens and who spend time in practicing sports..

As regard the academic performance of the studied population who are involved in the educational process, $49.9 \%$ of them got excellent assessment, 33.6\% got very good, $11.2 \%$ got good and 5.3\% got passable assessment. Also when assessing the appetite of our children, we found $61.4 \%$ have average appetite (2-3 meal/day), $23.1 \%$ have high appetite (3-5 meal/day) and $15.5 \%$ got low appetite (one meal/day).

The majority of the children in the study (62.9\%) prefer eating habit while watching TV or playing video games. Figure 3 shows the percentage of the daily/weekly food regimen included in the children's meal. 


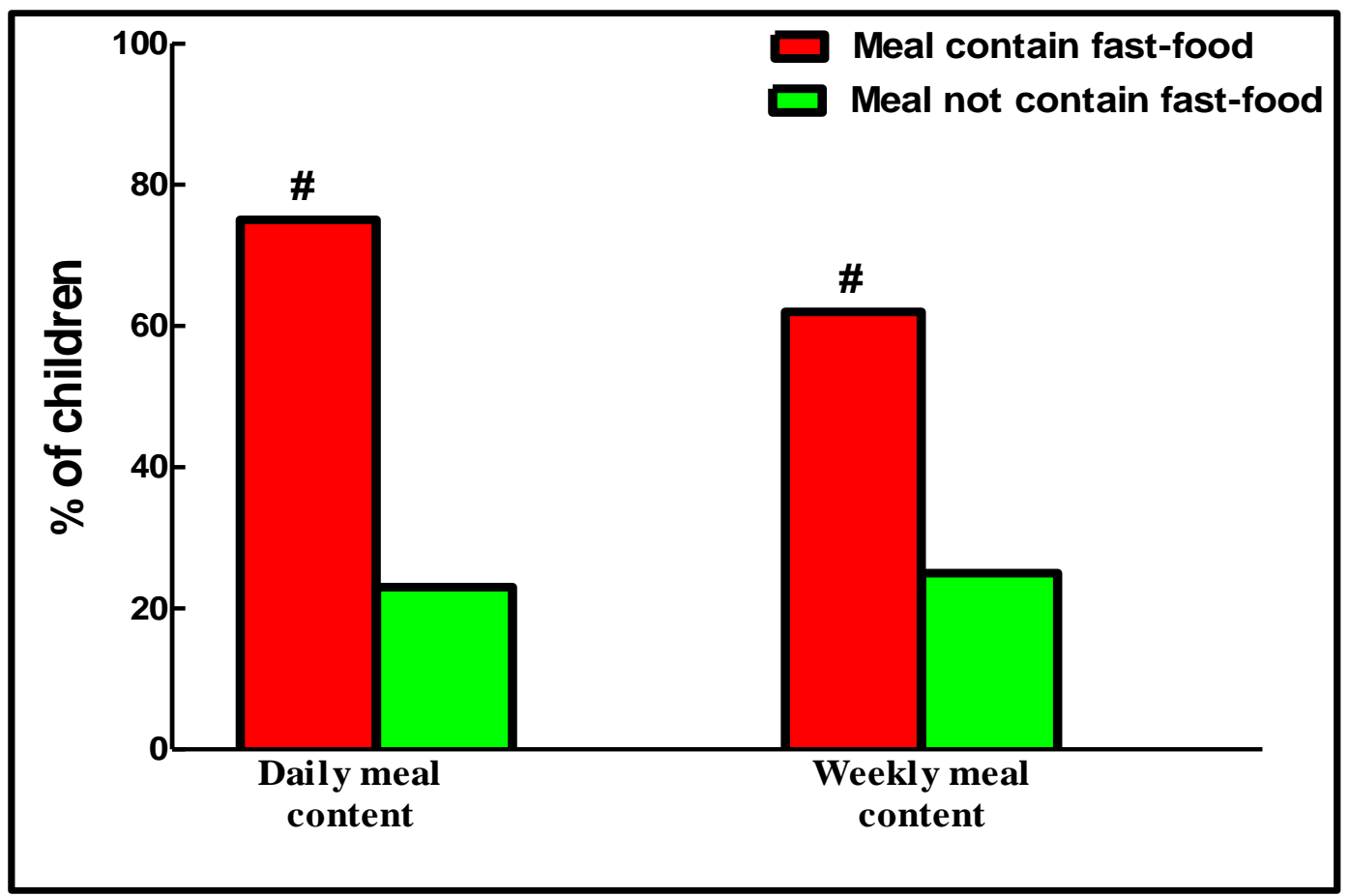

Figure 3:-Daily/Weekly children's meal content.

When asking about the preferred type of food preferred by the children, $65 \%$ of the parent's choose the fast food as the preferred one for their kids, Figure 4. The parents also suggested many reasons for preferring fast food. For example, its convenience, delicious taste.

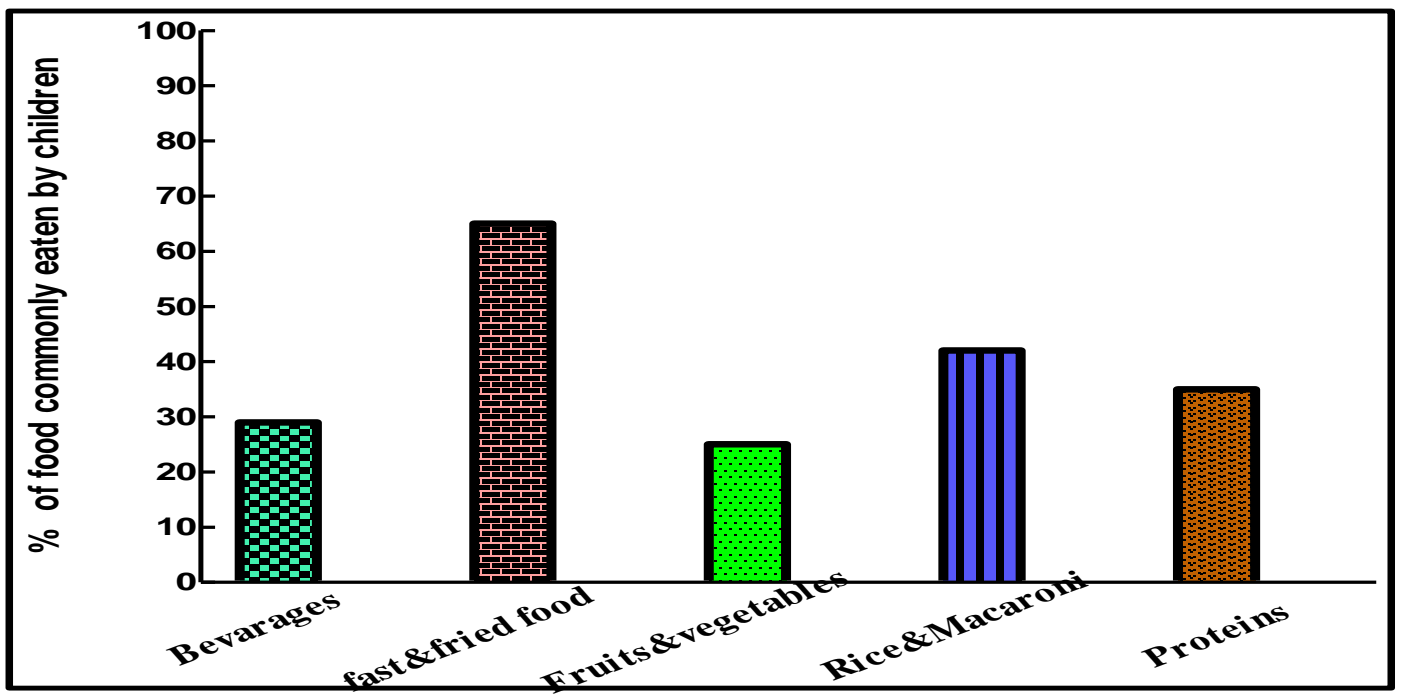

Figure 4:-Type of food that commonly eaten by children.

By investigating the peri-natal period of the studied population, we found that $78.9 \%$ of the parents have normal pregnancy events, only $21.1 \%$ have some pregnancy complications (e.g. gestational Diabetus, placental hemorrhage, hypertension and exposure to irradiation). Majority of children (86.5\%)were delivered 3.6.2 full term via spontanous vaginal delivary. Only $11.7 \%$ of them was admitted to NICU just after birth due to different causes (infection, jaundice, cyanosis) and the admission period in most of the admitted children did not exceed 2 weeks. 
The duration of breast feeding was significantly different between the studied population, where $24 \%$ of them were breast feed less than 6 months, $17.4 \%$ ranging from 6-12 months, 32.2\% were breast feed 12-24 months, while $10.9 \%$ were not breast feeding at all. External feeding was introduced to the children after 1 year in $56.2 \%$ of the studied population.

\section{Discussion:-}

BMI and height are parameter of good health status of children. Many factors can affect on the child stature and weight, some of these factors are watching TV, video games and lack of sleep which became very common among children these days .

This study mainly focus on how watching TV, video games and lack of sleep affect body weight and height in our society. The results of this study indicated that children spend more hours on TV, video games and have fewer hours of sleep are more likely to be obese and short in relation to those who spend less hours on TV, video games and have enough hours of sleep.

Previous investigations have cleared that there is a positive correlation between playing video games and child obesity (14). Another study showed that playing video games has a direct effect on the children's weight while watching television was not (15). This agrees with our results regarding video games which showed that children who spend more time playing video games are more prone to be obese than others. But on contrary to this study, our results shows that watching TV has also a relation to obesity among children, this may be because more hours spent on TV on our society and lead to less physical activity among our children .

In agreement to our study, there was a study about the affect of sleep hours on BMI of the child, this studyprove that children who had lack of sleep were 4.2 times more prone to have obesity (16).

Previous screening for parent length was done in Saudi Arabia (17). The result show that the average height for men in Saudi Arabia is $1.746(\mathrm{~m})$, while the average height for women in Saudi Arabia is 1.625 (m). Our study show significant decrease of parent length comparing with the previous screening result. It show that the average height for men is $1.70(\mathrm{~m})$ while the average height for women $1.58(\mathrm{~m})$.

Many studies show that there is no relation or affect of child behaviors and duration of sleep on the stature of the children (18)(19)(20). This is not in line with our study which proved that there was a significant short stature among children who are proved to have lack of sleep. our results is supported by a cross-sectional study in Japan prove that we should do psychological adjustment in children with achondroplasia (short stature) because stressors make them more (21)

\section{In Conclusion:-}

watching TV, playing video games and lack of sleep may increase the risk of developing obesity and short stature in Saudi children.We advise the community to reduce the children exposure to screens and giving children enough amount of sleep will be an effective approach for improving mental and physical health, This can be done via different ways using media and health education sessions in different places may be helpful.

\section{Study Limitations:-}

The number of the study population need to be increased and involves more Saudi regions and populations. 


\section{Reference:-}

1. PediatricsBarlow SEE .xpert committee recommendations regarding the prevention, assessment, and treatment of child and adolescent overweight and obesity: summary report. 2007 Dec;120

2. Whitlock EP1, Williams SB, Gold R, Smith PR, Shipman SA. Screening and interventions for childhood overweight: a summary of evidence for the US Preventive Services Task Force. 2005 Jul;116(1):e125-44.

3. Brownell KD1, Kersh R, Ludwig DS, Post RC, Puhl RM, Schwartz MB, Willett WC. Personal responsibility and obesity: a constructive approach to a controversial issue. 2010 Mar-Apr;29(3):379-87

4. Harvard T.H. Chan School of Public Health > Obesity Prevention Source 2015

5. Pilar A. Hernandez, Catherine H. Graham,Lawrence L. Master and Deborah L. Albert The effect of sample size and species characteristics on performance of different species distribution modeling methods. 24 OCT 2006

6. Average height.com , 2015

7. Eur J Pediatr,Simma B, Höliner I, Luetschg J. Therapy in pediatric stroke. 2013 Jul;172(7):867-75

8. Rachael Rettner, Sleep Could Fight Risk of Catching a Cold . August 2015

9. By AD Rogo , Aug 13, 2015

10. Mideastmedia.org, July 2014

11. Taveras EM, Rifas-Shiman SL, Oken E, Gunderson EP, Gillman MW. Short sleep duration in infancy and risk of childhood overweight.

12. Arch PediatrAdolesc Med. 2008 Apr;162(4):305-11

13. By http://www.livestrong.com/article/376383-obesity-in-children-video-games/

14. Jenni OG1, Molinari L, Caflisch JA, Largo RH . Sleep duration from ages 1 to 10 years: variability and stability in comparison with growth. Pediatrics. 2007 Oct;120(4):e769-76.

15. A Escobar at FlickrunderCreative Commons License.Childhood Obesity, Smoking, and Sexual Activity Linked to Media Exposure.december 2, 2008

16. A Levin and B Rodriguez.Video games rather than TV may be linked to childhood obesity.March 23, 2004

17. D McNamee.Interaction between reduced sleep and childhood obesity further examined.Mon 19 May 2014

18. Ian Langtree, Height Chart of Men and Women in Different Countrie. 2015

19. Jenni OG1, Molinari L, Caflisch JA, Largo RH . Sleep duration from ages 1 to 10 years: variability and stability in comparison with growth. Pediatrics. 2007 Oct;120(4):e769-76.

20. M C Gulliford, C E Price, R J Rona, and S Chinn.Sleep habits and height at ages 5 to 11.Arch Dis Child. 1990 Jan; 65(1): 119-122.

21. Hwang JW1, Seo JY2.Parents' perception about child's height and psychopathology in community children with relatively short stature.Epub 2015 Jun 30.

22. J ClinNurs, Nishimura N, Hanaki K. Psychosocial profiles of children with achondroplasia in terms of their short stature-related stress: a nationwide survey in Japan. 2014 Nov;23(21-22):3045-56 